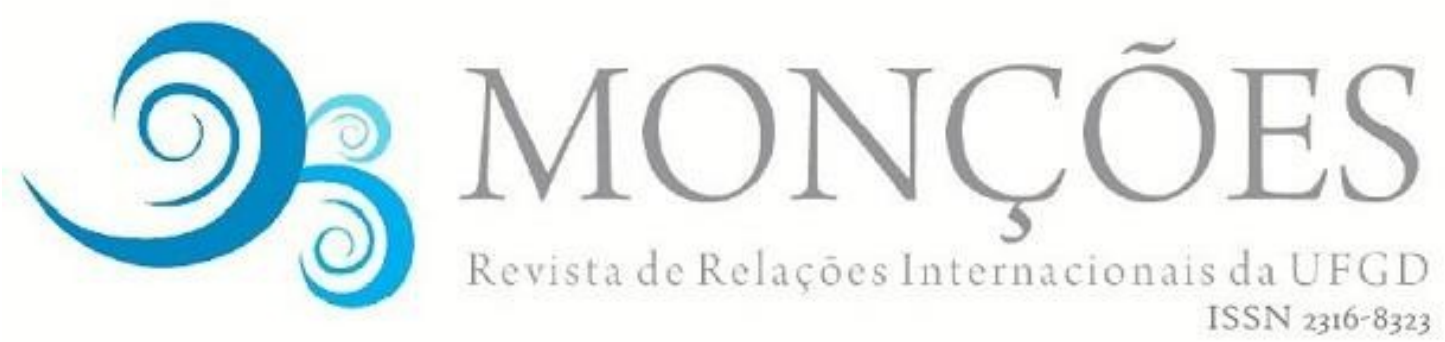

\title{
O ENSINO DE PORTUGUÊS COMO LÍNGUA DE ACOLHIMENTO E SEU PAPEL COMO FACILITADOR DO PROCESSO DE INTEGRAÇÃO DE IMIGRANTES VENEZUELANOS EM RORAIMA
}

\author{
Gustavo da Frota Simões \\ Coordenador do Curso de Relações Internacionais e Professor no \\ Programa de Pós-Graduação em Sociedade e Fronteiras da UFRR \\ gustavo.simoes@ufrr.br \\ Carolyne de Melo Ribeiro Tavares \\ Bacharel em Relações Internacionais pela Universidade Federal de Roraima. \\ carolynettavares@gmail.com

\begin{abstract}
Resumo: Este artigo tem como objetivo compreender de que maneira o ensino de Português como Língua de Acolhimento (PLAc) do Projeto Acolher da Universidade Federal de Roraima (UFRR) promoveu a integração do migrante venezuelano na sociedade roraimense. A hipótese é a de que o ensino de Português na metodologia língua de acolhimento oferece instrumentos linguísticos e conhecimentos sociais para que o imigrante se insira com melhor capacidade na sociedade de destino. Para tanto, analisou-se as teorias e o conceito de integração de imigrantes e refugiados, sobretudo o papel do ensino do idioma como língua de acolhimento e de conhecimentos culturais e cidadãos como facilitadores nesse processo. Além disso, uma vez que se trata de um fluxo migratório extraordinário, entender a imigração venezuelana para Roraima foi de grande importância, contextualizando a crise econômica, social e política da Venezuela e sua relação com o êxodo migratório. Ademais, descreveu o ensino de PLAc exercido pela Rede Acolher nos anos de 2016 a 2019 e como esse ensino facilitou o processo de integração dos imigrantes venezuelanos formados nesse curso.
\end{abstract}

Palavras chaves: Integração; Migração; Venezuelanos.

\section{THE TEACHING OF PORTUGUESE AS A LANGUAGE OF RECEPTION AND ITS ROLE AS A FACILITATOR OF THE INTEGRATION PROCESS OF VENEZUELAN IMMIGRANTS IN RORAIMA}

\begin{abstract}
This article had as its main objective to analyze how teaching Portuguese as a welcoming language of Acolher Project in the Federal University of Roraima promotes integration of the Venezuelan migrant in the society of Roraima. The hypothesis is that teaching Portuguese on the modality of welcoming language offers linguistic and social tools so the migrant can be integrated with greater skills in the society of destination. For this purpose, there were analyzed theories and the concept of integration of migrants and refugees, specially the role of the classes of the language and cultural knowledge as a facilitator in this process. Moreover, once it is about an extraordinary migratory flow, understanding the Venezuelan immigration to Roraima was of major importance, contextualizing Venezuela's economic, social and political crisis and its link with the migratory outflow. Beyond that, it described the teaching of Portuguese as a welcoming language by Acolher Project in the years of 2016 to 2019 and how it facilitated the processes of integration of Venezuelan students graduated in this course.
\end{abstract}

Key Words: Integration, Migration, Venezuelans. 


\section{INTRODUÇÃO}

Nos últimos anos o Brasil tem sentido os efeitos da crise política, social e econômica pela qual a Venezuela passa, principalmente Roraima, estado brasileiro que faz fronteira com o país e que tem enfrentado uma série de desafios com o aumento de imigrantes venezuelanos, representado por um significativo fluxo migratório no estado, principalmente na capital Boa Vista.

Em contextos como esse, ampliam-se as necessidades de criação de políticas públicas para melhor gerenciamento das novas demandas, inerentes a contextos de migração internacional. Acredita-se que as mencionadas políticas devem ser elaboradas de tal maneira que contemple as necessidades tanto dos migrantes quanto da sociedade receptora.

Nesse sentido considera-se fortemente que a administração das demandas emergentes em tal contexto se baseiem na promoção de integração, pensada neste trabalho como um processo bidirecional, que segundo a Organização Internacional para as Migrações (OIM), possui duas-vias de mútua adaptação entre migrantes e as sociedades receptoras nas quais os migrantes são incorporados social, econômica e culturalmente.

Embora o Brasil ainda esteja caminhando na consolidação de políticas públicas para imigrantes, no estado de Roraima já existem diversas ações sendo desenvolvidas no intuito de ajudar a minimizar os desafios que muitos imigrantes refugiados têm enfrentado. Dentre as ações, destaca-se o Projeto Acolher, desenvolvido por vários docentes e estudantes da Universidade Federal de Roraima, por meio do primeiro curso de Português como Língua Estrangeira e de Acolhimento do estado de Roraima, oferecendo ao mesmo tempo atendimento humanitário, educacional e cultural aos migrantes.

Neste artigo questiona-se de que forma o Ensino de Português como Língua de Acolhimento auxilia a integração do imigrante venezuelano em Roraima? Partimos da compreensão de que a aquisição da língua local ajuda o imigrante a se integrar à sociedade com maior facilidade e o ensino de Português como Língua de Acolhimento em Boa Vista tem papel importante para essa integração. Ademais, as implicações desta prática como facilitadora nos processos de integração do 
imigrante venezuelano em Boa Vista por meio de iniciativas como a da Rede Acolher.

O estudo tem teor qualitativo, levando em conta como ferramenta metodológica, dados advindos de experiências vivenciadas por participantes ativos do projeto Acolher na área do ensino de português para obtenção de evidências e perspectivas que essa prática tem gerado. Para desenvolver um diálogo coerente e consistente entre as temáticas abordadas neste trabalho, as análises se pautaram em estudos de teóricos como Anger e Strang, que enfatizam o ensino-aprendizagem de línguas como facilitador nos processos de integração. Ademais, são feitas referência a importantes teóricos da área linguística no Brasil.

A estrutura do artigo divide-se em três seções. Na primeira seção, descrevese a crise econômica, social e política da Venezuela para entender o contexto migratório que se configurou no Brasil, em especial em Roraima. Explora brevemente o histórico da Venezuela e sua atuação como receptor e emissor de migrantes. Ademais, examina o perfil do imigrante que chega em Boa Vista, seus potenciais e suas possibilidades de integração, sob uma análise do idioma.

$\mathrm{Na}$ segunda seção, expõe-se o referencial teórico, isto é, discute-se os conceitos de integração em contextos de migração internacional e a relevância da aquisição da língua local neste processo, mencionando algumas práticas em âmbito global. Destaca-se o aprendizado do Português como facilitador da integração do migrante à sociedade. A terceira seção descreve o Projeto Acolher desde sua criação até os dias atuais, analisando seus êxitos e desafios relacionando-os à teoria consolidada na primeira seção: a aquisição do idioma como facilitador da integração dos migrantes. Dialogando com a segunda seção, esta última analisa como os objetivos do projeto mencionado contemplam a integração do migrante e qual a natureza dessa integração.

Com este trabalho deseja-se contribuir para as discussões sobre o ensino de Português como Língua de Acolhimento para refugiados e imigrantes esperando que a partir delas sejam criadas reflexões no âmbito público, privado e no terceiro setor, nos quais pode-se promover integração em contextos migratórios internacionais. Tratando-se de uma prática educacional na maioria das vezes empreendida em universidades, pretende-se especialmente que essas discussões contribuam para a academia no que se refere à importância do ensino de línguas na modalidade de 
acolhimento, uma vez que possibilita a integração do migrante à sociedade. Para além disso, pretende-se consolidar essa prática como grande promotora de benefícios não apenas aos migrantes, mas a todos aqueles que se propõem aprendizes nesse processo.

\section{A MIGRAÇÃO VENEZUELANA EM RORAIMA}

O êxodo migratório venezuelano advém de uma crise no país que possui várias facetas, várias facetas políticas, econômicas e sociais. Dessa forma, esse movimento expresso em um significativo quantitativo de refugiados e migrantes venezuelanos já alcançou a marca de três milhões em todo o mundo, sendo considerado como o maior êxodo da história moderna da América Latina e do Caribe (ACNUR, 2018). Conforme o Relatório 2017/2018 da Anistia Internacional a Venezuela enfrenta uma das piores crises de direitos humanos de sua história recente, instigada em grande parte pelo governo, levando a crescentes protestos gerados pelo aumento da inflação e uma crise humanitária causada pela escassez de alimentos e de suprimentos médicos.

De acordo com Vaz (2017) a crise venezuelana possui diversas dimensões, fundamentadas na interação de três fatores básicos, sendo o primeiro relativo ao conflito entre a urgência de governabilidade e ao regime de Nicolas Maduro; o segundo fator se refere ao crescimento desordenado da economia, doméstica e internacional; o último fator diz respeito ao aprofundamento e a generalização da crise social que se reflete nos elevados índices de criminalidade e violência.

Levando em conta tais questões, Pareja (2018) defende o multidimensionalíssimo da crise na Venezuela, afirmando que a origem do conflito é de caráter político, centrado primordialmente na luta pelo poder presidencial, acentuado com a posse presidencial do Presidente Nicolas Maduro, que proporcionou uma série de mudanças na conjuntura interna venezuelana de caráter econômico, social e político. Quarenta anos após a instituição de seu governo de forma democrática, a Venezuela passa a ser governada por Hugo Chávez (19542013), o qual se mantém no poder até 2013. Seu desempenho político sob o Sistema Populista de Conciliação de Elites em função do bipartidarismo permitiu a 
inclusão social, econômica e política do setor da população que havia entrado na linha da pobreza desde o início dos anos 90.

Com a morte de Chávez, em 2013, Nicolas Maduro assume o poder e se vê diante de uma crise iniciada ao final de 2012 e que em 2013 já dá evidências claras de uma crise fiscal, com severo impacto na inflação, escassez de produtos de primeira necessidade e perda do valor real da moeda (VERA, 2015). Sendo assim, entre 2002 e 2018 se realizaram pelo menos quatro iniciativas de diálogo para a regulação do conflito político entre o governo e a oposição, todas articuladas após momentos de intensos conflitos e violência e possuíam em comum a busca pela manutenção ou alcance do poder presidencial. É possível afirmar, que a crise venezuelana no campo político é fortemente relacionada ao conflito entre o atual governo e a oposição.

No que tange às questões políticas e de governabilidade, Vaz (2017) indica que a crise se evidencia na reprovação ao governo que ultrapassa, no presente (2017) os 70\%, além da perda de apoio parlamentar. Este resultado refletiu de modo contundente à crescente insatisfação popular com o governo de Nicolas Maduro, que resultou nos protestos ocorridos no início de 2014 que produziram mortes e que levaram à prisão de lideranças oposicionistas.

De acordo com a Anistia Internacional (2018), um dos grandes motivos do descontentamento populacional deve-se à crise de abastecimento de alimentos e outros produtos de consumo básicos, de medicamentos e aos sucessivos cortes de energia em todo o país e que recrudesceu ao longo do tempo. Segundo Rosales (2018) o governo bolivariano, iniciado com Chávez, seguido de Nicolás Maduro, baseou seu modelo de desenvolvimento quase que, exclusivamente, na produção e exportação petroleira. A exportação de petróleo bruto representa mais de $95 \%$ de renda em moedas estrangeiras para o país. Segundo Urribarrí (2016), desde 2013, a economia venezuelana já apresentava sérios problemas com a inflação crescente e uma lacuna entre o dólar oficial e o paralelo cada vez maior, o que se deve em grande medida ao declínio significativo dos preços do petróleo, que ocorrem desde o final de 2012.

Sobre essa condição, é compreensivo que a condição econômica é um dos maiores problemas enfrentados pelos venezuelanos no dia a dia, o que significa que 
todos os custos, desde comida às contas em geral estão crescendo à um nível acentuado ao mesmo tempo em que o valor da moeda continua a cair.

Tendo em vista que a natureza da Crise Venezuelana é caracterizada por sua complexidade e âmbito multidimensional.

[...] a falta de confiança no Governo do presidente Maduro e suas políticas econômicas, o discurso do Presidente (que continua culpando à "oligarquia" das crises), a escassez de divisas oficiais e a instabilidade política, tiveram como consequências uma pressão cada vez maior no mercado paralelo de dólares, incrementando no diferencial cambial, ocasionando uma maior inflação e, portanto, fazendo cada vez mais caro a importação de qualquer tipo de produto. (URRIBARRI, 2016, p.367-368)

Nesse sentido, compreende-se que a crise venezuelana tem seus aspectos interconectados. A crise econômica, por exemplo, se reflete em outros planos, como o social, já que a hiperinflação diminui drasticamente o poder de compra da população. Conforme o Relatório 2017/2018 da Anistia Internacional, em dezembro de 2017, a cesta básica para uma família de cinco pessoas custava 60 vezes mais do que o salário mínimo. Nesse contexto, a condição econômica na Venezuela, consequentemente, levou à situação de crise de abastecimento de alimentos nas prateleiras dos supermercados, havendo a falta de produtos básicos nos comércios locais, gerando, assim, uma condição tensa entre a população crescendo o nível de violência nas cidades (JAROCHINSKI SILVA, 2017).

A violência é, portanto, a ação da população insatisfeita com a atual condição de vida na Venezuela, tornando-os cada vez mais vulneráveis. Essa situação permite aumentar a onda de furtos advindos do desespero da população faminta e protestos duramente reprimidos pelas forças policiais. Assim, permite-se analisar a dinâmica do fluxo migratório da população venezuelana. A situação política e econômica são os principais elementos que justificam o êxodo migratório na Venezuela, implicando na busca da população por melhores condições de vida.

\section{INTEGRAÇÃO DE IMIGRANTES E REFUGIADOS}

Para melhor compreensão do conceito de integração, é necessário conhecer o contexto no qual se insere para identificar de que maneiras se difere de outros tipos de integração. No contexto de migração internacional, que segundo o 
dicionário da OIM (2009, p. 40) envolve processos através dos quais estrangeiros se deslocam para um país, a fim de aí se estabelecerem. Referente à modalidade migratória de refugiado, a Convenção de 1951 das Nações Unidas, define-se como sendo qualquer pessoa que:

[...] temendo ser perseguida por motivos de raça, religião, nacionalidade, grupo social ou opiniões políticas, se encontra fora do país de sua nacionalidade e que não pode ou, em virtude desse temor, não quer valerse da proteção desse país, ou que, se não tem nacionalidade e se encontra fora do país no qual tinha sua residência habitual em consequência de tais acontecimentos, não pode ou, devido ao referido temor, não quer voltar a ele (ACNUR, 1951, p. 02).

Neste sentido, ao reconhecer os status quanto à condição de migrante, permite compreendê-lo como sujeito migrante inserido na sociedade receptora, possibilitando a integração social, conceito que segundo Simões (2017) é um termo amplamente utilizado nas Ciências Sociais e cuja definição também é de difícil formulação, pois é necessário levar em conta diferentes termos em diferentes épocas. Sendo assim, elaborar políticas de integração no contexto migratório é algo dificultado pelo fato de o conceito de integração ser muito amplo e possuir diversos significados. Robinson (1998) expressa que tal integração na verdade é um conceito caótico, uma palavra usada por muitos, porém interpretada de maneiras distintas estudos, além de contextualização, individualista e controversa.

Esta ideia é reforçada por Castles et al. (2001) os quais afirmam que não existe uma definição, teoria ou modelo de integração de refugiados ou imigrantes de caráter única e amplamente aceita, sendo um conceito que continua a ser controverso e amplamente debatido. Sendo assim, o conceito de integração amplamente estudado e debatido perante os estudos acadêmicos, permite a existência de uma série de interpretações por meio de uma diversidade de modelos capazes de serem aplicados às condições migratórias.

Nesse contexto, a definição de integração expressada pelo ACNUR (2007) como um processo mútuo e dinâmico contempla aspectos importantes da discussão permitindo destacar a importância de ser uma via de mão dupla e multifacetada. Além disso, o conceito caracteriza-se por ser um processo contínuo que exige deveres dos refugiados e dos Estados, sem, no entanto, indicar quais deveres são esses. A OIM vai ao encontro dessa definição pois também sustenta que o processo 
de integração depende de diversos atores para atingir seus fins plenamente, pois afirma que "a responsabilidade pela integração não é de um grupo em particular, mas de vários atores: do próprio imigrante, do Governo de acolhimento, das instituições e da comunidade" (OIM, 2008). Além disso, reforça que entre estes atores a relação é de troca e mutualidade em diversos aspectos, uma vez que integração é definida como processo bidirecional de mútua adaptação entre migrantes e a sociedade receptora nas quais os migrantes são incorporados na vida social, econômica, cultural e política desta sociedade. A Europa apresenta instituições e conselhos de migração debatem questões migratórias como, por exemplo, o Conselho Europeu (1998) que afirma que o processo de integração possui uma dinâmica bidirecional, na qual os imigrantes mudam a sociedade ao mesmo tempo em estes a integram ao Estado receptor.

Em meio às diversas definições sobre integração, é pertinente mencionar conceitos adjacentes que as complementem, como por exemplo o de coesão social. De acordo com a OIM (2017), a integração implica no conjunto de responsabilidades conjuntas para os migrantes e comunidades de acolhimento e, neste amplo entendimento, incorpora outras noções relacionadas, como a inclusão social e a coesão social.

Historicamente, tem-se que o conceito de Coesão Social foi desenvolvido na tentativa de promover a língua francesa na base da justiça social. Apesar da identificação entre Quebec e a língua francesa também ser almejada pelo governo do país, a ênfase está na promoção de aulas do idioma francês como base para estabelecer acesso igualitário a educação e emprego (PAGÉ, 2005). Numa perspectiva semântica, o Dicionário Houaiss (2001) define coesão como solidariedade entre elementos de um todo; união. Em consonância com essa definição e de acordo com Demireva (2017) não há uma definição de coesão social, mas identifica seu conceito semelhante aos termos como solidariedade e sentimento de união manifestando a oposição quanto à desordem e/ou desorganização social.

No entanto, assim como em integração, não há uma definição unificada sobre Coesão Social sobre o que o autor acima mencionado também afirma que a inexistência dessa definição traz uma série de desafios principalmente no que diz 
respeito à avaliação da coesão social, levando às verificações através de indicadores mais subjetivos como os níveis de confiança entre os indivíduos.

A falta de uma definição unificada levanta uma variedade de desafios para a definição da coesão social. A maioria dos estudiosos assumem que o alto níveis de coesão social e capital social em uma comunidade se refletirão em altos níveis de confiança entre os indivíduos e o cumprimento de normas sociais (DEMIREVA, 2017, p. 02).

Segundo a OIM (2008), Integração e coesão social são áreas políticas que se enquadram principalmente em jurisdição local e nacional, o que não impede a intervenção e provisão de normas e ações possíveis e comuns ao nível global e supranacional. Assim, a manutenção da coesão social pode ser considerada como um dos principais objetivos da integração e mais do que garantir o bem-estar do migrante também é um importante elemento para o funcionamento e estabilidade social do país receptor. Acredita que "migrantes bem integrados também estão mais propensos a alcançar seus próprios potenciais e trazer uma contribuição positiva à vida econômica, social e cultural no país de destino" (OIM, 2008, p.17). Além disso, a OIM (2008) acredita que a integração é uma questão transversal e multissetorial que diz respeito a áreas políticas que abordam as esferas econômica, social, legal, cultural e cívica e que impactam todos os aspectos da vida dos migrantes e de suas comunidades.

Tendo em vista que o processo de integração implica na emergência de diversos atores e demandas, é importante conhecer as partes interessadas que podem ser envolvidas nesse processo de integração, pois conforme Appave e David (2017) a integração é um processo inerente a experiência migratória e "[...] é portanto de interesse chave para as partes interessadas relativas a migração notavelmente aos próprios migrantes e a sociedades receptoras" (APPAVE E DAVID, 2017, p. 01)

A identificação dos interesses, funções e responsabilidades de todas as partes interessadas relevantes na integração dos migrantes pode permitir alcançar a coordenação e a complementaridade dos seus esforços e possibilitar uma estratégia global coerente (OIM, 2008, p. 29) 
Segundo a ACNUR (2018), a Declaração de Nova York estabeleceu os elementos chaves para uma resposta mais eficaz em contextos de migração, que pode ser observado em seu Quadro Abrangente de Respostas a Refugiados no qual mais do que responder ao deslocamento de refugiados por meio [...] das lentes puramente humanitárias" (ACNUR, 2018, p. 4) e há o desejo de promover uma resposta mais sistemática e sustentável que beneficie tanto os refugiados quanto as comunidades que os recebem. Isso leva a um olhar mais analítico sobre os agentes e quanto sua atuação, que segundo a ACNUR (2018) passam a ser os seguintes: governo a nível nacional e local, instituições financeiras internacionais e regionais, agências das Nações Unidas e Organizações Não-Governamentais - ONGs por meio de parcerias, refugiados, setor privado e atores da sociedade civil. Dessa maneira, é possível garantir respostas mais sustentáveis já que une esforços humanitários e de desenvolvimento desde o início das crises, fortalecendo e tornando mais inclusiva a prestação de serviços no contexto migratório.

Nesse sentido, segundo a OIM (2008) o procedimento de integração necessita envolver uma comunicação entre os Estados e os diversos agentes de forma a possibilitar a formulação de abordagens políticas abrangentes e coerentes. Dessa maneira, identifica-se os demais agentes representados por Organizações Intergovernamentais, a participação da Sociedade Civil, atores do setor privado e os próprios migrantes. No contexto abordado neste estudo, o foco vai para a atuação da sociedade civil a qual desempenha um papel importante na integração e que segundo a OIM "por meio de suas diversas estruturas, representa uma multiplicidade de perspectivas e interesses, e podem trazer uma importante contribuição ao processo de integração" (OIM, 2008, p. 42, tradução nossa).

\section{A IMPORTÂNCIA DO ENSINO DE LÍNGUAS - IDIOMA FACILITADOR}

Após uma breve discussão sobre o termo "Integração", é possível afirmar que mesmo sendo um termo de difícil consenso, a integração no contexto migratório tem sido uma questão de debate por algum tempo. O caminho de duas vias a que se refere o processo de integração diz respeito não apenas à dinâmica de promoção 
deste processo, mas também aos benefícios que proporciona. É o que se infere quando Mallows (2014) afirma que

o aprendizado de línguas não é apenas do interesse de migrantes. Para os decisores e formuladores de política é também uma questão chave. Vivemos numa época de altos níveis de migração. Por razões sociais houve um crescente movimento de pessoas entre os países (MALLOWS, 2014, p. 38).

Tal ideia pode ser corroborada ao se observar a proposta de análise da eficácia das políticas de acolhimento elaborada através de um estudo de Ager e Strang (2008) que apresenta quatro grandes domínios para a integração, a saber: marcadores e meios, conexões sociais, facilitadores e fundação. Apesar de os autores afirmarem que não há como basear a integração apenas nesses indicadores de sucesso', adotaremos essa análise pois apresenta uma série de fatores que corrobora com a visão de integração adotada neste trabalho, e vai ao encontro de ideias como a de que é uma constituição de símbolos e laços de pertença a uma sociedade, defendida por Pires (2012).

Figura 1 - Estrutura Conceitual de Definição dos Principais Domínios de Integração
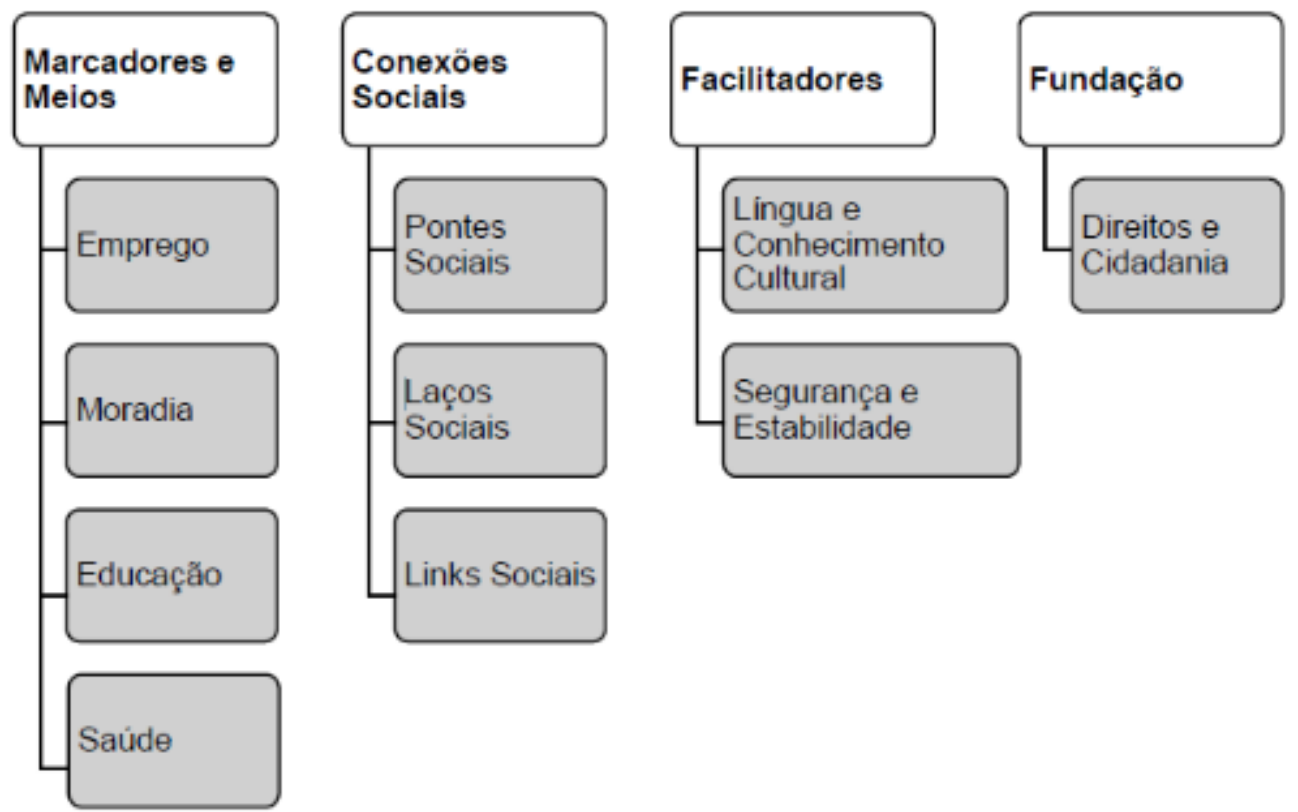

Fonte: Elaborado pelos autores, baseada em Ager e Strang (2008). 
Quanto à Figura 1, atentar-se-á ao domínio de Facilitadores, no qual língua e conhecimento cultural são "indicadores de integração" e, segundo Ager e Strang (2015), definem como uma das áreas chaves de competência cultural percebidas como necessárias para uma integração efetiva na sociedade, pois ser capaz de falar a língua principal da comunidade receptora é identificado como fundamental no processo de integração. Todas as esferas estão muito bem estruturadas e em coesão, fazendo com que sejam interdependentes. Por exemplo, dentro do domínio Conexão Social há três subdomínios a saber: pontes sociais, laços sociais e ligações sociais que, à primeira vista, podem parecer similares.

No entanto, o primeiro subdomínio se refere a conexões que ligam membros de um grupo; o segundo trata das conexões entre grupos; e o terceiro diz respeito a conexões entre indivíduos e estruturas do Estado, como serviços governamentais. Laços sociais descrevem "conexões que ligam membros de um grupo, e conexões sociais entre tais grupos, links sociais referem-se à conexão entre os indivíduos e as estruturas do estado, tais como serviços governamentais" (Ager e Strang 2008, p.181).

Ager e Strang (2015) indicam que algumas das principais críticas feitas ao modelo proposto se referem à dinâmica e as inter-relações entre estes domínios, sobre o que afirmam que "[...] a inter-relação complexa dos fatores mapeados dentro da estrutura, no entanto, sinalizou que esse 'fluxo' estrutural é uma característica inadequada da estrutura, uma vez que não há setas direcionais na composição" (AGER e STRANG, 2015, p. 603).

Ainda assim, chegam à conclusão de que a inter-relação entre acesso a emprego e aquisição linguística talvez seja o padrão mais bem estabelecido. Sob essa perspectiva, Ager e Strang (2008) afirmam que apesar de tudo, a integração continua sendo significativa tanto quanto uma meta de política estatal como um resultado específico para projetos referentes a refugiados. No âmbito estatal, ao mesmo tempo em que é uma solução, a integração por meio da língua e conhecimento cultural também pode enfrentar adversidades.

Sob as perspectivas de que a integração é um processo bidirecional, a competência da língua também constitui um desafio às comunidades 
receptoras, principalmente naquelas em que é difícil prover serviços essenciais como assistência médica (AGER E STRANG, 2018, p. 182).

Em se tratando do processo de integração em si, Ager e Strang (2008) destacam que a integração, independente de que maneira se realize, começa desde o momento de chegada do refugiado no novo país. Mais do que isso, a efetividade da integração é influenciada pelas experiências do momento de chegada. Por exemplo, o processo de cidadania pode ser acelerado ou retardado dependendo da proficiência da língua e/ou conhecimento cultural que o refugiado demonstre. Destacam também a eficácia de recursos práticos e online e cursos de formação com especialistas selecionados em educação de migrantes e treinamento sobre diversidade e teoria da segunda língua no atendimento às necessidades dos migrantes.

Os fluxos migratórios trazem consigo uma série de desafios, principalmente, no que diz respeito ao gerenciamento de diferenças culturais entre a população local e aos imigrantes. Para evitar que se chegue a contextos de intolerância e xenofobia, é oportuno investir em sensibilizações para melhor convivência com as diversidades. Sobre isso, Ager e Strang (2010) afirmam que para que se construam pontes entre grupos fechados é necessário haver oportunidades para que as pessoas se conheçam e intercambiem recursos para benefícios mútuos, em ambientes tais como escolas ou no mercado local.

Mais do que ensino/aprendizagem da língua, os migrantes também destacam o valor do conhecimento cultural nos processos de integração, seguindo a dinâmica de um processo bidirecional. Isso significa que é necessário que se promovam espaços e momentos nos quais os migrantes e a população local intercambiem conhecimento cultural. Sabendo dos diversos aspectos relativos ao ensino de línguas como prática de extremo valor em contextos de migração internacional, no qual coexistem culturas diferentes, se faz necessário consolidá-la como indispensável mecanismo promotor da integração. Isso porque se considera que aquisição do idioma local atua como facilitador do processo integrativo, fazendo possível o alcance elementos básicos como emprego, moradia, educação e saúde. 
Quanto à modalidade de ensino de línguas abordado neste trabalho, Grosso (2010) esclarece o conceito de Português como Língua de Acolhimento (PLAc), associando-o a contextos migratórios, atribuindo certo caráter afetivo:

\begin{abstract}
expressão que se associa ao contexto migratório, mas, que sendo geralmente um público adulto, aprende o português não como língua veicular de outras disciplinas, mas por diferentes necessidades contextuais, ligadas muitas vezes à resolução de questões de sobrevivência urgentes, em que a língua de acolhimento tem de ser elo de interação afetivo (biredicional) como primeira forma de integração (na imersão linguística) para uma plena cidadania democrática. (GROSSO, 2010, p. 68).
\end{abstract}

Em vista disso, percebe-se que o Português como Língua de Acolhimento apresenta uma série de outros desafios distintos daqueles encontrados em contextos tradicionais de ensino de línguas, com o PLAc há uma abordagem diferente, na qual fatores extralinguísticos relacionados a contextos migratórios precisam ser considerados.

O PLAc se realiza em contextos de resposta emergencial tendo como a afetividade um dos pilares de sua estrutura, constituindo-se assim como uma prática muito conveniente em contextos de migração internacional, pois promove de maneira mais facilitada a integração do migrante à sociedade aonde se destinou. A seguir, pretende-se compreender as configurações do êxodo migratório venezuelano para Roraima e conhecer a população migrante para melhor análise das formas pelas quais o ensino de PLAc permite viabilizar um processo de integração exitoso do fluxo venezuelano na sociedade roraimense.

\title{
A REDE ACOLHER COMO INICIATIVA DE INTEGRAÇÃO DO PORTUGUÊS COMO LÍNGUA DE ACOLHIMENTO
}

Como visto na seção 2, o estado de Roraima, situado no extremo norte do Brasil, vem sofrendo um aumento do fluxo migratório com o deslocamento de venezuelanos desde o ano 2015, com a entrada de aproximadamente 40 mil venezuelanos no estado nos últimos três anos, de acordo com o Alto Comissariado para Refugiados da ONU (ACNUR), que tem cruzado a fronteira Brasil/Nenezuela em busca de melhores condições de vida, devido à crise política, econômica e social que enfrenta o país vizinho. Neste cenário, o estado de Roraima, pouco experiente em relação a fluxos migratórios internacionais, depara-se com certo despreparo 
social, econômico e político com a expressiva chegada de imigrantes que cresceu desde o ano 2016. Isso leva a um cenário no qual há grande quantidade de migrantes à procura de uma vida melhor, em busca de medicamentos e alimentos e fugindo da pobreza causada pela crise econômica e política do país vizinho. Mais do que isso, há também a aspiração por integrarem-se à sociedade do Estado acolhido.

A partir do reconhecimento do perfil do migrante que chega no estado de Roraima, fica evidente sua qualificação como sujeitos que desejam inserir-se no mercado de trabalho no estado mencionado. É interessante observar os meios que permitem que a integração ocorra, principalmente aqueles baseados no preceito de que a migração é um processo inevitável, mas que com boa gestão, torna-se um evento profícuo e motor de mudanças benéficas a todos os envolvidos.

\begin{abstract}
Ainda que a própria história da humanidade e a ampla gama de estudos técnicos e acadêmicos atestem que a migração internacional sempre foi e continua sendo benéfica para o desenvolvimento de todas as sociedades de acolhida, a sociedade brasileira ainda engatinha na compreensão de que os fluxos imigratórios recentes podem trazer uma série de benefícios às cidades de acolhidas, quando bem gerenciados pelas autoridades nacionais e locais (JAROCHINSKI SILVA e SAMPAIO, 2018, p. 739).
\end{abstract}

No entanto, as bases deste pensamento ainda estão em construção, pois para Camargo e Lima (2018) a chegada dos venezuelanos a Roraima causou um forte impacto na opinião pública do estado. Ao mesmo tempo em que, muitos grupos se organizaram para realizar ações de apoio, houve também reações adversas e marcadas pela xenofobia.

Segundo Silva et al (2017) desde meados da segunda metade do século XX, os estudos sobre as migrações indicam que há certa complexidade na questão social que envolve o tema e para o fato de que sua análise e compreensão não poderiam partir apenas de um viés cognitivo, mas de um conjunto de disciplinas que compõem as Ciências Sociais como a História, Geografia, Demografia, Direito, Sociologia, Psicologia Social, Antropologia, Linguística e Ciência Política. Nesse sentido, como sugere Kuhlmann (2016), nos contextos migratórios é pertinente questionar de que maneira práticas educacionais promovem experiências capazes de fundamentar $\mathrm{o}$ acolhimento e o empoderamento do sujeito migrante desassociando-os dos estereótipos que podem colocá-lo às margens da sociedade. 
Dentre as iniciativas que promovem esse tipo de experiências e respondem às necessidades peculiares dos migrantes venezuelanos em Boa Vista, destaca-se aqui o Projeto de Extensão Acolher, apoiado pela Universidade Federal de Roraima. Ciente de seu papel e compromisso com a sociedade, em consonância com sua missão de:

contribuir e comprometer-se com a formação de cidadãos éticos, com capacidade crítico-reflexiva, e competentes em suas áreas profissionais, por meio do ensino público e gratuito, da pesquisa e da extensão, que respeitem as diversidades étnicas e culturais, promovendo o convívio entre as muitas populações deste espaço fronteiriço e participando da construção do desenvolvimento de Roraima, sugerindo reflexões e soluções para as temáticas que ultrapassem as fronteiras do estado na procura de oferecer soluções, suporte e ajuda por meio do ensino (UFRR, 2015, p. 16).

Assim, colaborou com a criação do Projeto de Extensão Acolher, inicialmente do curso de Antropologia, e posteriormente desenvolvido por vários docentes e estudantes do curso de Relações Internacionais, por meio do primeiro curso de Português como Língua Estrangeira e de Acolhimento do estado de Roraima, oferecendo ao mesmo tempo atendimento jurídico e cultural aos migrantes.

Sobre a trajetória e nomenclaturas, segundo Júlia Faria de Camargo, uma das idealizadoras do Projeto Acolher

o curso surge como projeto de uma disciplina de RI, fica vinculado durante alguns meses na Rede Acolher (projeto de extensão do curso de antropologia), depois passa a ser cadastrado como Projeto de Extensão Português para Acolhimento do curso de Relações Internacionais por alguns meses e depois passa a ser parte das atividades da Cátedra Sérgio Vieira de Mello. Atualmente é parte de uma iniciativa da Ericsson que busca promover conhecimento através da tecnologia. (Fonte: entrevista)

É relevante ressaltar o conceito de Língua de Acolhimento aplicado ao projeto, descrito por Barbosa e São Bernardo:

Ao falarmos em língua de acolhimento referimo-nos ao prisma emocional e subjetivo da aprendizagem dessa nova língua, sem perder de vista a relação conflituosa que se apresenta no contato inicial do imigrante com a sociedade acolhedora (BARBOSA; SÃO BERNARDO, 2018, p. 435). 
Grosso (2010) propõe a utilização do termo língua de acolhimento, amparado por uma visão interculturalista de língua e de suas práticas de ensinoaprendizagem (ibidem, p. 73-74). Relaciona-se às especificidades de um novo público que vem se fazendo presente no contexto migratório internacional, composto por imigrantes vítimas de processos de deslocamento forçado. A autora assim resume sua definição de PLAc:

[...] é um conceito que geralmente está ligado ao contexto de acolhimento, expressão que se associa ao contexto migratório, mas que, sendo geralmente um público adulto, aprende o português não como língua veicular de outras disciplinas, [...] ligadas muitas vezes à resolução de questões de sobrevivência urgentes, em que a língua de acolhimento tem de ser o elo de interação afetivo (bidirecional) como primeira forma de integração [...] para uma plena cidadania democrática (GROSSO, 2010, p. 74).

E é concernente a contextos de migração, uma vez que a expressão "língua de acolhimento" surge no contexto português após o aumento dos movimentos migratórios para Portugal, sobretudo no ano 2000, procedentes de países do leste europeu e dos continentes africano e asiático (PEREIRA, 2017, p. 119).

No fluxo migratório cada vez mais forte que se desenvolve em Roraima, na cidade de Boa Vista o Projeto Acolher é coerente com as expectativas de integração indicadas, principalmente por meio do ensino de Português como Língua de Acolhimento. Barbosa e São Bernanrdo (2015) afirmam que:

Nessa situação, aprender a língua do país receptor promove inclusão social e profissional dos imigrantes. Esse conhecimento leva a uma maior igualdade de oportunidades para todos, facilita o exercício da cidadania e multiplica qualificações enriquecedoras àqueles que chegam e àqueles que os recebem (BARBOSA E SÃO BERNARDO, 2015, p. 1)

A iniciativa teve suas primeiras atividades em abril de 2017, como parte da matéria de Organizações Internacionais, ministrada pela professora Júlia Faria Camargo do curso de Relações Internacionais, com a realização de aulas de português ministradas por alunos da matéria mencionada. As aulas de português se deram no primeiro abrigo voltado a migrantes venezuelanos ${ }^{1}$. No entanto, o espaço

\footnotetext{
${ }^{1}$ Região em que estava concentrada a população venezuelana. Atualmente, o abrigo do Pintolândia é designado à comunidade indígena Warao.
} 
possuía poucos recursos estruturais, o que resultava em um ensino educacional mais limitado, se tratando de um ambiente pouco propício a aprendizagem. Decidiuse então levar essa atividade para a Universidade Federal de Roraima, por diversas razões, sendo a principal relacionada à compreensão de que a Universidade é um espaço onde se deve "promover e difundir a educação e a criação cultural, e o desenvolvimento científico e reflexivo da sociedade, garantindo sua qualidade, sua natureza pública" (UFRR, 2013, p. 04) fazendo possível, portanto, a utilização da sua estrutura física voltada para ensino-aprendizagem. Ademais, a transferência deste tipo de atividade para o campus implica também na inserção do corpo docente e discente das mais diversas áreas nas iniciativas voltadas ao acolhimento da população migrante, promovendo grande troca e "a integração cultural na perspectiva da pluralidade dos povos da região e de sua integração internacional" (UFRR, 2013, p. 04).

Essa perspectiva é bastante conveniente tendo em vista que dialoga muito bem com o conceito de integração em contextos migratórios internacionais, de ser um processo de mão dupla no qual ambas as populações (migrante e receptora) se beneficiam e vai ao encontro da percepção de que "sensibilizar os migrantes e as populações de acolhimento para lidar com a diferença e cultivar uma atitude positiva em relação à diversidade a longo prazo são as principais estratégias de integração cultural" (OIM, 2008, p. 29).

Uma vez na UFRR, as aulas realizaram-se no Núcleo Amazônico de Pesquisa em Relações Internacionais (NAPRI), sob a coordenação de Júlia Faria Camargo com gestão e execução voluntária de alunos do curso de Relações Internacionais. Neste primeiro momento, as aulas tinham como grande intuito a promoção de um espaço onde os migrantes pudessem não apenas adquirir conhecimento, mas relacionar-se com ele como agente passivo e ativo neste processo de saberes.

Ressalta-se que, desde o início das atividades do projeto, tinha-se a noção de que "o domínio da língua é um dos fatores fundamentais na integração do refugiado, principalmente pelo fato de a barreira linguística condicionar severamente o acesso a qualquer outro aspecto referente à sua sobrevivência [...]" (PEREIRA, 
2017 , p. 125) e, por isso, "surge como indispensável relacionar o processo da integração do sujeito com o desenvolvimento das suas competências em línguaalvo", como afirma Grosso (2007, p. 02).

Além do ensino de português para fins comunicativos, havia em certa instância o intuito de promover algum tipo de acolhimento aos migrantes tendo em vista a situação de vulnerabilidade que enfrentavam. Relaciona-se, portanto, ao que afirma Barbosa e Ruano (2016) sobre a condição de refúgio que impõe desafios adicionais a esse processo, distintos dos encontrados em contextos tradicionais de ensino de Português como Língua Estrangeira - PLE, pois o migrante refugiado encontra-se submetido a uma série de pressões de natureza econômica, social e legal que o colocam em uma situação de vulnerabilidade (Barbosa e Ruano, 2016, p. 323) refúgio e hospitalidade.

As perspectivas individuais sobre a língua-alvo, sua auto imagem, os planos para o futuro, como a necessidade urgente de aprendizagem para inserção no mercado de trabalho e integração na sociedade, podem criar dificuldades no processo de aprendizagem. A própria tensão do movimento migratório de fuga, somada, muitas vezes, ao afastamento dos laços familiares e linguístico-culturais também pode contribuir para essa situação" (AMADO, 2013).

Portanto, desde o início as aulas de português tinham teor de acolhimento, mas só com o tempo passou a se desenhar como tal com maior consistência através de contribuições diversas de especialistas em PLAc, dos quais podemos destacar Lúcia Maria de Assunção Barbosa e José Carlos Paes de Almeida filho, que vieram in loco para compartilhar e multiplicar os saberes sobre o ensino de PLAc, além de conhecerem propriamente o contexto migratório em que se realizavam as aulas, na cidade de Boa Vista.

O intuito de acolher nesta modalidade de ensino de português também foi pensado em diversos outros aspectos, como por exemplo, na estruturação de escalas de professores voluntários, buscando sempre diversificar as duplas para que houvesse sempre diversos saberes e sotaques. Além disso, haviam contínuas reuniões para alinhar as práticas em sala, buscando promover um espaço que combinasse aprendizado e acolhimento. 
Com o tempo e chegada de profissionais com maior expertise, consolidamse práticas pedagógicas voltadas a um ensino que tem como função mais do que gerar um conhecimento da língua como um sistema isolado, com suas regras e configurações desagregadas de seu uso na vida real. Tais preceitos vão ao encontro de Almeida Filho (2002), pois este afirma que: "a nova língua para se desestrangeirizar vai ser aprendida para e na comunicação sem se restringir apenas ao domínio de suas formas e do seu funcionamento enquanto sistema" (ALMEIDA FILHO, 2002, p. 12). Para isso, segundo o autor, é importante que o aprendiz se envolva em situações reais de interação e de comunicação efetiva na nova língua, por isso a necessidade de estratégias que permitam essa comunicação de maneira rápida e efetiva, princípio basilar do PLAc do Projeto Acolher.

Com tal estruturação, ofereceram-se cursos com 120 horas de duração, com duas turmas em níveis diferentes (básico e avançado), uma vez por semana, coordenado por professores do curso de Relações Internacionais e ministrado por acadêmicos de graduação e pós-graduação de diversos cursos da UFRR. Além da multiplicidade de saberes, o curso de português contou com a participação de voluntários com rica diversidade linguística: roraimenses, cariocas, manauaras, paulistas, paraenses, africanos e venezuelanos se revezaram na tarefa de aprender e ensinar o Português como Língua de Acolhimento.

Diversidade acertada uma vez que obedece a noção de um ensino que envolve múltiplos saberes, e consonante ao que afirma Caldeira (2012), além de desenvolver as habilidades linguístico-discursivas, a proposta fundadora da Língua de Acolhimento - PLac objetiva promover:

[...] a interacção real na vida quotidiana, as condições de vida, as convenções sociais. Na língua de acolhimento são privilegiadas áreas que promovam o conhecimento sociocultural, o saber profissional, a consciência intercultural, as relações interpessoais, bem como a partilha de saberes, favorecendo a interajuda e ultrapassando estereótipos pela interação e pelo diálogo intercultural (CALDEIRA, 2012, p. 50).

Como afirma Amado (2011), tal diálogo de culturas, entendido como interculturalidade é um pilar importante do ensino de línguas em contextos migratórios pois promove o entendimento e tolerância entre os povos. Prova disso é 
a consolidação de tal princípio em outras práticas dentro de contextos migratórios internacionais.

O aprendente de uma língua torna-se plurilíngue e desenvolve a interculturalidade. As competências linguísticas e culturais [...] permitem, ao indivíduo, o desenvolvimento de uma personalidade mais rica e complexa, uma maior capacidade de aprendizagem linguística e também uma maior abertura a novas experiências culturais. (CONSELHO DA EUROPA, 2001, p. 73).

Sob essa perspectiva, o foco das aulas eram as abordagens comunicativa e intercultural e ao final eram oferecidos aos alunos imigrantes certificados de conclusão do curso de português, com $40 \mathrm{~h}$, totalizando 405 alunos, entre homens, mulheres e crianças com formatura realizada no âmbito da Universidade Federal de Roraima, especificamente no Colégio de Aplicação.

Segundo Camargo, o número de mulheres aumentou consideravelmente depois da inclusão das crianças no Portuguesinho. Em geral, os principais desafios encontrados na execução das atividades concentram-se na dificuldade de uma adaptação rápida, que consiga ampliar o público participante, uma vez que o fluxo migratório é cada vez mais crescente e a procura pelas ações de extensão da universidade aumentam cada vez mais. A sustentabilidade financeira do projeto também representa uma dificuldade, uma vez que não existem recursos próprios para as atividades e o número de bolsistas extensionistas são muito poucos.

No total o curso alcançou até o momento cerca de 630 alunos em todas as suas atividades, com parcela considerável atendida nas aulas de Português. Atualmente o Português como Língua de Acolhimento está sendo desenvolvido através de uma parceria com a Ericsson, sob o viés do aprendizado da língua tendo como principal ferramenta a tecnologia, promovendo inclusão digital, voltada para adultos e crianças, como parte das atividades da Cátedra Sérgio Vieira de Mello².

\footnotetext{
${ }^{2}$ A partir de 2017 a UFRR passou a ser a primeira Universidade do norte do país a compor a Cátedra Sérgio Vieira de Mello (CSVM), iniciativa entre o Alto Comissariado das Nações Unidas para Refugiados (ACNUR) e centros universitários e Universidades do Brasil com objetivo de estimular ações de ensino, pesquisa e extensão com temas voltados ao refúgio. Nesse processo, foi essencial a articulação do Projeto Acolher com o curso de Português como Língua de Acolhimento (PLAc) com o apoio da Cátedra Sérgio Vieira de Melo (CSVM) -
} 
Segundo a Ericsson (2018) o projeto, intitulado "Technology for Good Lab", foi concebido em 2017 após uma solicitação do governo brasileiro para que a Ericsson implementasse uma solução tecnológica que pudesse melhorar sua resposta à situação de migração venezuelana para o benefício dos migrantes e da população local no estado de Roraima. O laboratório deste projeto, que iniciou suas atividades em setembro de 2018, é composto por duas salas que oferecem inclusão digital com aulas de português para adultos e crianças, oferecidas em parceria com a universidade e prevê que após um ano de funcionamento, o laboratório digital terá impactado diretamente cerca 480 pessoas.

Com a implementação do mencionado projeto, as aulas ainda tinham como grande intuito o ensino para além da língua, constituindo-se como um espaço de recepção e escuta sensível. No entanto, as ferramentas utilizadas para tanto mudaram significativamente, tendo em vista que tinha como principal pressuposto a inclusão digital. Sendo assim houve uma mudança grande na questão metodológica, ao aliar tecnologia com português, algo no mínimo inovador.

\section{CONSIDERAÇÕES FINAIS}

Tendo em vista o exposto, este trabalho tomou como temática ensino de Português como Língua de Acolhimento e seu papel como facilitador do processo de integração de imigrantes venezuelanos em Roraima, provendo do estabelecimento de uma discussão sobre iniciativas como a do Projeto Acolher como prática capaz de proporcionar integração. Isso porque nos últimos anos o Brasil tem sentido os efeitos da crise política, social e econômica pela qual a Venezuela passa, principalmente Roraima, estado brasileiro que faz fronteira com o país. Assim, faz-se indispensável a discussão sobre políticas públicas locais que prevejam o acolhimento e a inserção destas populações na realidade dos países que as recebem. Neste sentido, o projeto abordado neste trabalho surge com o intuito de oferecer um dos primeiros recursos para a inserção dessas pessoas: o ensino da língua portuguesa.

ACNUR, que além de difundir o Direito dos Refugiados visa promover a formação acadêmica e a capacitação de professores e estudantes neste tema. 
De maneira geral, este trabalho teve como grande propósito oferecer bases para a compreensão das questões migratórias discutindo termos como "migrante", "integração" e "coesão social". Além disso, analisa práticas relacionadas a essas questões de maneira global. Nesse sentido considera-se fortemente que a administração das demandas emergentes em contextos de migração internacional se baseia na promoção de integração, como um processo bidirecional, que possui duas vias de mútua adaptação entre migrantes e as sociedades receptoras nas quais os migrantes são incorporados social, econômica, cultural e politicamente.

Pode-se considerar também que em contextos de migração internacional, ampliam-se as necessidades de criação de políticas públicas para melhor gerenciamento das novas demandas, percepção já adotada por países com histórico mais largo em fluxos migratórios de grande intensidade. Dentre diversas práticas, destacamos neste trabalho aquelas que se referem ao ensino de línguas pois acredita-se que este tipo de política promove a satisfação de necessidades tanto dos migrantes quanto da sociedade receptora.

Sob o viés da linguagem, apoiou-se na teoria de que o idioma é um facilitador nos processos de integração, base para todas as outras facetas relacionadas a este processo, a saber: emprego moradia, educação e saúde. Se não é possível se comunicar minimamente essas necessidades se tornam cada vez mais distantes de serem sanadas. Portanto, a aquisição da língua local é de suma importância para o migrante, uma vez que é a partir dela que se afrouxam os primeiros nós para sua inserção na sociedade.

Nessa perspectiva, mencionou-se uma modalidade específica de ensino de língua estrangeira dedicada à população migrante: o Português como Língua de Acolhimento, que se realiza em contextos migratórios tendo a afetividade e acolhimento como alguns dos pilares de sua estrutura, constituindo-se assim como uma prática muito conveniente em contextos de migração internacional pois promove de maneira mais facilitada a integração do migrante à sociedade aonde se destinou. Apesar da leitura de práticas de integração em contextos migratórios distintos, acredita-se que cada fluxo tem suas peculiaridades, desafios e benesses. 
Por isso se faz importante conhecê-las. Sendo assim, a segunda seção do trabalho se dedicou ao econômico inter-relacionadas ao exôdo migratório para Roraima.

Por meio dos dados referentes ao perfil dos migrantes venezuelanos que chegam à Roraima, foi possível analisar como a integração dos mesmos poderia ser feita de maneira a beneficiar todos os envolvidos, tanto a comunidade receptora quanto os migrantes em si. Com essas informações foi possível estabelecer relação entre o ensino de Português como Língua de Acolhimento e a integração dos alunos na sociedade do estado, integração esta que se realiza em diversas esferas: no mercado de trabalho, relacionamentos, acesso à educação, entre outros. Apesar da falta de registro em relação a empregabilidade é um fato que as aulas de português do Acolher promovem integração do migrante venezuelano na sociedade do estado de Roraima.

Além disso, é importante pontuar a existência e conquistas do projeto por meio de suas diversas parcerias, seja com a universidade, com a sociedade civil e até mais recentemente com o setor privado, especificamente com a Ericsson. Podese inferir que o grande benefício da realização do Projeto Acolher na universidade ademais da cessão do espaço, foi a inserção do público discente e docente nas atividades do projeto, de maneira voluntária, sejam na ministração de aulas ou em orientação jurídica para os migrantes, promovendo uma troca de saberes rica e constante.

No entanto, o grande número de voluntários apesar de enriquecedora provoca uma alta rotatividade que pode ser prejudicial em processos educacionais, nos quais é necessário a figura de referência no aprendizado. Por outro lado, com o crescimento da equipe de instrutores de português como língua estrangeira, houve a necessidade de maior conhecimento sobre essa modalidade de ensino para consolidar ainda mais a atividade. Isso possibilitou a vinda de profissionais e estudiosos altamente qualificados na área do ensino de Português como Língua Estrangeira (PLE) e Português como Língua de Acolhimento (PLAc), referências no Brasil e no mundo: Professora Dra. Lúcia Barbosa e o Professor Dr. Almeida Filho, ambos da Universidade de Brasília. 
Já na parceria com o setor privado, o Projeto Acolher ganhou uma nova roupagem, principalmente, no que diz respeito às ferramentas para o ensinoaprendizagem e possibilitou significativo avanço nas questões comunicativas, seja entre migrante e familiares ou migrante e sociedade acolhedora. No âmbito de formação, o projeto prevê remuneração a toda equipe colaboradora e isso é um ponto positivo no sentido de diminuir a rotatividade da equipe, principalmente dos professores, possibilitando um processo de ensino mais sólido e contínuo.

É relevante pontuar que não se podem comparar as fases do projeto em suas diferentes parcerias, pois em cada uma delas há demandas e conquistas diferentes. Mas a partir dessa leitura, é possível afirmar que o Projeto Acolher tem um caráter de adaptabilidade e flexibilidade altamente positivo pois consegue conversar com as diversas demandas de maneira a acolher todos os atores envolvidos, para que haja benefícios mútuos.

Conclui-se que o Projeto Acolher cumpre papel importante no cenário de migração internacional que se desenvolve no estado de Roraima, principalmente nos anos de 2017 e 2019 quando de fato desenvolve suas atividades no campo do ensino de português. Trouxe benefícios não apenas a um público, mas a todos que se propuseram a apoiá-lo, o que não é tarefa fácil e mais ainda se tratando de um estado que nunca havia lidado com um fluxo de tamanhas proporções e com pouca estrutura para tanto. Por meio dessa iniciativa, promoveu-se a atuação intensa dos alunos e das pessoas da sociedade civil nas atividades desenvolvidas, algo marcante nesse processo.

Por fim, foi possível perceber uma interdisciplinaridade na gerência dos processos de integração, pois não se refere apenas às ciências sociais, mas perpassa por uma série de disciplinas, dentre elas as Relações Internacionais. $O$ mesmo ocorre com a prática do ensino de Português como Língua de Acolhimento, que não necessariamente deve estar atrelada exclusivamente à área de Letras, pois envolve uma série de temas concernentes a múltiplos saberes, que podem ser administrados por profissionais e acadêmicos de diversas áreas. 


\section{REFERÊNCIAS}

ACNUR. Atualização sobre a Venezuela (Venezuela Update) $<$ https://www.unmultimedia.org/avlibrary/asset/2217/2217274>. Acesso em 14 de agosto de 2018.

ALMEIDA FILHO, J. C. P. Dimensões comunicativas no ensino de línguas. Campinas: Pontes, 2002.

ALMEIDA FILHO, J. C. P.; CUNHA, M. J. C. (2007). Projetos iniciais no ensino de português para falantes de outras línguas. Brasília: Editora da UnB

AMADO, R. S. Português como Segunda Língua para comunidades de trabalhadores transplantados. Revista Siple, Brasília: Sociedade Internacional Português Língua Estrangeira. 2 Ed., 2011.

. "O ensino de Português como Língua de Acolhimento para refugiados". Revista Siple, Brasília: Sociedade Internacional de Português Língua Estrangeira, 2013.

ANISTIA INTERNACIONAL - INFORME 2017/2018. O Estado dos direitos humanos no mundo. Reino Unido: Anistia Internacional, 2017.

ALTO COMISSARIADO DAS NAÇÕES UNIDAS. Convenção Relativa ao Estatuto dos Refugiados (1951). Disponível em: $<$ https://www.acnur.org/fileadmin/Documentos/portugues/BDL/Convencao relativa a o Estatuto dos Refugiados.pdf>. Acesso em: 13 out. 2018.

APPAVE, G.; DAVID, I. Integration that Values Diversity: Exploring a Model for Current Migration Dynamics. Genebra: IOM, 2017.

ÁLVAREZ DE FLORES, R. La dinámica migratoria colombo-venezolana: evolución y perspectiva actual. Geoenseñanza, Vol. 9, núm. 2, Universidad de los Andes: San Cristobal, 2004.

AGER, A.; STRANG, A. Understanding Integration: A Conceptual

Framework. Journal of Refugee. Vol. 21, n. 2. Nova lorque: Oxford University Press. 2008.

BARBOSA, L. M. A; SÃO BERNARDO M. A. Língua de Acolhimento. In: CAVALCANTI L. et al (Orgs.). Dicionário Crítico de Migrações Internacionais, verbete Língua de Acolhimento. Brasília, DF: UnB, 2017.

CALDEIRA, P. A. M. A imigração em Portugal: o português, língua de acolhimento e as problemáticas da identidade linguística e cultural. 161 f. 2012. Tese (mestrado em Letras). Faculdade de Letras, Universidade de Lisboa, 2012. 
CASTLES, Stephen. Et al. Integration: mapping the field. Report of a project carried out by the Centre for Migration and Policy Research and Refugee Studies Centre, University of Oxford. Oxford University Press, 2001.

Comissão Europeia. Communication From The Commission To The European Parliament, The Council, The European Economic And Social Committee And The Committee Of The Regions. Bruxelas, 2011. Disponível em: $<$ https://eurlex.europa.eu/LexUriServ/LexUriServ.do?uri=COM:2011:0455:FIN:EN:PD F>. Acesso em: 14 dez. 2018.

DEMIREVA, N. Briefing: Immigration, Diversity and Social Cohesion. The migration Observatory at the University of Oxford. 2017.

DI BRIENZA, M. "Poblacióny Migraciones". Revista SIC, num. 600. Caracas: SIC, 1997.

ERICSSON. Digital inclusion for refugees: Technology for Good @ RoraimaDisponível em: <https://www.ericsson.com/en/blog/2018/10/digital-inclusionfor-refugees-technology-for-good--roraima>. Acesso em: 10 Mar 2019.

FORREST, R.; KEARNS, A. Social Cohesion, Social Capital and the Neighbourhood. Urban Studies. $2001 . \quad$ Disponível em: $<$ https://www.researchgate.net/publication/46214297 Social Cohesion Social Capit al and the Neighbourhood>. Acesso em: 22 jan. 2019.

GROSSO, M. J. As competências do Utilizador elementar no contexto de acolhimento. In: ANÇÃ, M. H. (Org.). Actas do Seminário Língua Portuguesa e Integração. Aveiro: Universidade de Aveiro, 2007.

. Língua de acolhimento, língua de integração. Horizontes de Linguística Aplicada, v. 9, n. 2, Brasília, 2010.

HOUAISS, Antônio. Dicionário Houaiss da Língua Portuguesa. Rio de Janeiro: Objetiva, 2001.

International Organization for Migration - IOM. Migrants and the host society: partnerships for success International Dialogue on Migration. 2008. Disponível em: $<$ https://publications.iom.int/system/files/pdf/idm 11 en.pdf>. Acesso em: 03 jan. 2019.

. Migration trends in the Americas. 2018. Disponível em: $<$ https://robuenosaires.iom.int/sites/default/files/Informes/Tendencias Migratorias Na cionales en Americas Venezuela EN Julio 2018 web.pdf>. Acesso em: 03 set. 2018.

benefits of migration. s/d.

. Integration and Social Cohesion: key elements for reaping the 
JAROCHINSKI SILVA, J. C.; SAMPAIO, C. As ações decorrentes da migração de venezuelanos para o Brasil - Da acolhida humanitária à interiorização. In: ANNONI, D. Direito Internacional dos refugiados e o Brasil. Brasilia: GEDAI, 2018.

KUHLMANN, M. C. M. de A. Pelo direito de falar: práticas de ensino, acolhimento e empoderamento em contextos migratórios. In: Seminiário Migrações internacionais, refúgios e políticas, 2016, São Paulo. Migrações internacionais, refúgios e políticas. São Paulo/Campinas: Nepo/Unicamp, 2016. p. 1-7.

LOPEZ, A. P. de.; DINIZ, L. R. A. Iniciativas jurídicas e acadêmicas para o acolhimento no Brasil de deslocados forçados. Revista da SIPLE, no prelo.

MAHER, T. M. A educação do entorno para a interculturalidade e o plurilingüismo. In: KLEIMAN, A. B.; CAVALCANTI, M. C. (orgs.) Lingüística Aplicada: suas faces e interfaces. Campinas: Mercado de Letras, 2007.

MAYA, M. L. El colapso de Venezuela. ¿Qué sigue? In. LEGLER, Thomas; PONT, Andrei Serbin; GARELLI-RÍOS, Ornela. Pensamiento propio. Buenos Aires: Cries, 2018.

Organização Internacional para as Migrações - OIM. Glossário sobre Migrações. Direito Internacional sobre migração. 2009. Disponível em: <https://www.acm.gov.pt/documents/10181/65144/Gloss\%C3\%A1 rio.pdf/b66532b28eb6-497d-b24d-6a92dadfee 7b >. Acesso em: 20 maio 2018.

PAGE, M. La francisation des immigrants au Québec en 2005 et après. In: STEFANESCU, A.; GEORGEAULT, P. Le français au Québec: les nouveaux défis. Québec: Les Editions Fides, 2005.

PAREJA, F. A. Mecanismos alternativos de diálogo y negociación en el conflicto político de Venezuela (2002-2018). In. LEGLER, Thomas; PONT, Andrei Serbin; GARELLI-RÍOS, Ornela. Pensamiento propio. Buenos Aires: Cries, 2018.

PEREIRA, G. F.; O Português como Língua de Acolhimento e interação: a busca pela autonomia por pessoas em situação de refúgio no Brasil. v. 17, n. 1, p. 118-134. São Paulo: Cadernos de Pós-Graduação em Letras, 2017.

PIRES, R. P. "O problema da integração". Revista Sociologia, Faculdade de Letra da Universidade do Porto, v. 24, 2012.

PONT, A. S. La crisis humanitaria en Venezuela y su impacto regional:

migración, seguridad y multilateralismo. In. LEGLER, Thomas; PONT, Andrei Serbin; GARELLI-RÍOS, Ornela. Pensamiento propio. Buenos Aires: Cries, 2018.

RIBAS, C. V. La migración en Venezuela como dimensión de la crisis. In. LEGLER, Thomas; PONT, Andrei Serbin; GARELLI-RÍOS, Ornela. Pensamiento propio. Buenos Aires: Cries, 2018. 
ROSALES, A. El agotamiento del modelo de neo-extractivismo en Venezuela: causas económicas y sus implicancias globales. In. LEGLER, Thomas; PONT, Andrei Serbin; GARELLI-RÍOS, Ornela. Pensamiento propio. Buenos Aires: Cries, 2018.

SIMÕES, G. "Venezuelanos em Roraima: migração no extremo norte do país". Mundorama - Revista de Divulgação Científica em Relações Internacionais, 2017.

; CAVALCANTI, L.; OLIVEIRA, T.; MOREIRA, E.; CAMARGO, J. Resumo executivo - Perfil socidemográfico e laboral da imigração venezuelana no Brasil. Conselho Nacional de Imigração. Brasília, DF: CNIg, 2017.

TAVARES, C. M. R. Arquivo iconográfico sobre o ensino da língua portuguesa na UFRR. Boa Vista: UFRR, 2019.

UNIVERSIDADE FEDERAL DE RORAIMA. Curso de Relações Internacionais. Projeto Político Pedagógico do curso de Bacharelado Em Relações Internacionais. Boa Vista, 2007. 73 p.

2013.

. Conselho Universitário. Estatuto: Universidade Federal de Roraima,

URRIBARRI, R. A. S. Venezuela (2015): Un régimen híbrido en crisis. Revista de Ciencia Política., Vol. 36. n. 1, 2016.

VAZ, A. A crise venezuelana como fator de instabilidade regional: Perspectivas sobre seu transbordamento nos espaços fronteiriços. Análise Estratégica, no.2, 2017.

VERA, L. Venezuela 1999-2014: Macro-Policy, Oil Governance and Economic Performance. Comparative Economic Studies. Venezuela: FACES, 2015.

Recebido em: 16/05/2019

Aprovado em: 17/03/2020 